\title{
Examining the Effectiveness of Physical Activity on Mental Health among Bosnian Refugees: A Pilot Study
}

\author{
Huaibo Xin ${ }^{1, *}$, Ajlina Karamehic-Muratovic ${ }^{2}$, Nicole Aydt Klein ${ }^{1}$ \\ ${ }^{1}$ Department of Applied Health, Southern Illinois University Edwardsville, United States \\ ${ }^{2}$ Department of Anthropology and Sociology, St. Louis University, United States
}

Copyright $\mathrm{C} 2017$ by authors, all rights reserved. Authors agree that this article remains permanently open access under the terms of the Creative Commons Attribution License 4.0 International License

\begin{abstract}
This pilot study aimed to reduce Bosnian refugees' vulnerability to and severity of mental disorders and sustain their mental health through adopting culturally appropriate and tailored physical activity. The study used the Community-Based Participatory Research approach and the quasi-experimental study design. A total of 35 participants in the intervention group received 12-week regular physical activity while 35 participants in the control group received 12-week educational materials concerning mental health. The effectiveness of the intervention was measured by the validated and culturally and linguistically competent instrument, Mental Health Inventory (MHI)-38. At the end of the study, both intervention and control groups demonstrated statistically significant improvement on the scales of MHI-38 either within or between groups. The study served as a non-clinical example to sustain, replicate, and expand the current intervention activities among the rest of the Bosnian community and other refugee/immigrant populations in the U.S. regarding their mental health well-being.
\end{abstract}

Keywords Physical Activity, Mental Health, Bosnian Refugees

\section{Introduction}

A significant number of research studies, including multiple systematic reviews and meta-analyses among thousands and thousands of refugee individuals with different ethnic backgrounds, have demonstrated that regardless of age and ethnicity, international refugees are more likely to experience psychiatric distress (e.g., major depression, major anxiety, post-traumatic stress disorder [PTSD]) than general populations [1-3]. The relationship between refugees' mental disorders and their pre-migration, migration, and post-migration traumas/stressors has also been well established [4-6]. For instance, according to a review of 113 out of 840 studies on refugees' mental health, published from 1998 to 2009, including ten systematic reviews and five meta-analyses, traumas/stressors associated with migration that contributed to refugees' poor mental health status included famine, war, religious or political prosecution, disruption of social support and network, harsh living conditions in refugee camps, exposure to violence, uncertainty about future, discrimination and social exclusion, culture and language barriers, and economic distress [2]. As the number of refugees worldwide is rapidly growing, recent literature has re-emphasized the contribution of these traumatic experiences among refugee adults, adolescences, and children resettled in different countries to their mental well-being [7-11]. Abou-Saleh and Hughes [7], in their article, titled "Mental health of Syrian refugees: looking backwards and forwards," suggested that future effort to improve refugees' mental health should focus on "mental health and psychosocial support services that go beyond clinical services and include efforts to strengthen community support mechanisms and nonclinical interventions to strengthen coping mechanisms."

The 1992-1995 genocide in Bosnia and Herzegovina left approximately 150,000 people dead and more than two million displaced. Many of these individuals became refugees in countries, such as Germany, U.S., Australia, Sweden, Croatia, Netherlands, and the United Kingdom. As a result of war, Bosnians have lost family members, community and social connections, important life projects, social roles, and property. They have also experienced human rights violation and humiliation, poverty, and threats to life, resulting in high prevalence and incidence of PTSD, major depression, anxiety and comorbidity [12-15]. For example, in 1996, using the validated Hopkins Symptom Checklist-25 (HSCL-25) and Harvard Trauma Questionnaire, a cross-sectional survey was carried out among 534 Bosnian refugee adults living in a Croatia refugee camp. About $39.2 \%$ and $26 \%$ of study participants reported symptoms that met the criteria of Diagnostic and Statistical Manual of Mental Disorders (DSM) IV for PTSD or major depression, respectively; and 20.6\% reported symptoms of comorbidity of both PTSD and major 
depression [12]. After a three-year follow-up, in 1999, out of 534 refugee participants, 376 remained living in the region. Using the same survey instruments, about $45 \%$ of the participants who were diagnosed with PTSD or major depression or both continued to have these mental disorders; about $16 \%$ of participants who were asymptomatic in 1996 developed either one or both disorders in 1999 [13]. Moreover, a random sample of 163 Bosnian refugee adult women resettled in Sweden was compared with 392 Swedish-born women. By adopting the HSCL-25 and Posttraumatic Symptom Scale, the findings suggested that the prevalence rate of PTSD among the Bosnian women was $28.3 \%$, and they had significantly higher risks of symptoms of depression, anxiety, and other psychological distress than did the Swedish-born women. Bosnian women were also found to have more than nine times more odds of developing major depression [14]. Similarly, in the U.S., using the standardized PTSD Symptoms Scale, Communal Traumatic Experiences Inventory, and the Global Assessment of Functioning (DSM-IV), one study measured the prevalence of PTSD among 34 Bosnian refugee adults. Of the 34 participants, 25 were diagnosed with PTSD at baseline, and 15 were diagnosed with PTSD after 1 year. Although a majority of the PTSD refugee patients had a decrease of the severity of their symptoms, the prevalence remained substantial. Older refugees appeared to have more severe symptoms [15].

Over the past 50 years, numerous epidemiologic and clinical studies have documented a wide range of significant health benefits, including mental health benefits, associated with physical activity [16-18]. In the last decade, the Centers for Disease Control and Prevention (CDC), as a key partner of the World Health Organization for global physical activity promotion, has been actively involved in every major step of integrating physical activity with chronic disease prevention and health promotion through public health research/interventions, public health policies, and public health curricula, making this as one of its institutional missions [17]. Physical activity has become central to good public health practice both globally and nationally [17]. Regular physical activity serves as a protective factor for mental health. It reduces individuals' vulnerability to chronic mental disorders, such as major depression, anxiety, PTSD, bipolar disorder and schizophrenia. Moreover, it contributes to the reduction of the severity of the symptoms as well as the disability related to mental disorders $[16,18]$. Research findings among different populations are consistent as to the benefits of physical activity in mental health $[16,18]$. However, rarely have studies been conducted to improve refugees' mental health through physical activity interventions [19]. There is also no existing study examining the effectiveness of how physical activity can strengthen Bosnian refugees' mental health. Approximately 70,000 Bosnian refugees/immigrants were resettled after the Bosnian War (1992-1995) and are currently living in the Greater St. Louis area, MO. Mental health issues have taken a tremendous toll on their productivity, overall quality of life, and life expectancy [20]. The overall goal of this pilot research study is to reduce Bosnian refugees' vulnerability to and severity of mental disorders and sustain their mental health through adopting culturally appropriate and tailored physical activity.

\section{Materials and Methods}

\subsection{Theoretical Framework}

The study was supported by the Community-Based Participatory Research approach (CBPR), which was adopted to design and implement tailored and culturally appropriate physical activity for the target population. A generally accepted and synthesized definition of CBPR is "a collaborative research approach that is designed to ensure and establish structures for participation by communities affected by the issue being studied, representatives of organizations, and researchers in all aspects of the research process to improve health and well-being through taking action, including social change" [21]. It particularly responds to the needs of addressing health disparities and community empowerment among minority and socially and economically disadvantaged communities. CBPR fulfills the community engagement core of both National Institutes of Health (NIH) funded Clinical and Translational Science Awards (CTSA) and CDC funded prevention research [22]. It significantly strengthens the research and health outcomes [23].

\subsection{Study Design}

Built upon the premises of the CBPR, the study used quasi-experimental study design. The quasi- experimental design had both intervention and control groups. The intervention group was asked to conduct at least five 30-minute or three 50-minute self-selected and monitored moderate-intensity physical activity practices per week in their spare time for 12 consecutive weeks. The control group received materials in Bosnian regarding general knowledge/techniques of improving mental health by mail each week for 12 consecutive weeks. The effectiveness of the proposed physical activity was evaluated both within the group and between the groups through pre- and post-surveys.

\subsection{Sampling}

A majority of Bosnian refugees arrived in the U.S. in the early 1990s due to the Bosnian War. Including refugees, immigrants, and American-born children, the Bosnian community has continuously grown, and approximately 70,000 currently reside in the Greater St. Louis area, MO. It accounts for $20 \%$ of the City of St. Louis's total population. The community has become the largest Bosnian "city" outside of Bosnia [20]. Today, Bosnia refugees call the Greater St. Louis area home. Based on the current literature 
on physical activity and mental health, using $\mathrm{G}^{*}$ Power software, the sample size was determined by the statistical analysis, effect size, power, and significance level. Statistically, the total sample size for this quasi-experimental study was 60 participants with effect size of 0.65 , power of 0.8 , and significance level of 0.05 (one-tailed), so 30 participants were assigned to either intervention or control group [24]. The target population groups, however, were hard-to-reach because of their language and cultural barriers, and relatively frequent movement due to their financial constraints and the nature of their occupations (e.g., truck driver). Given this attrition, the total sample size was increased by $10 \%$ to $15 \%$, which brought the final sample size up to 70 with 35 per group. Both criteria sampling and snowball sampling were applied to participants' recruitment. The inclusion criteria included the following: (1) originally being resettled in the U.S. as a refugee, (2) being resettled in the Greater St. Louis area; (3) being aged 25 to 64 years old (Bosnian children, seniors, and immigrants will be included in a future study because of current limited resources for budget and personnel); (4) not exercising regularly and/or adequately determined by the Physical Activity Pre-Screening Questionnaire (Bosnian) for the intervention group; not planning to exercise during the study period for the control group, and (5) willingness to complete the 12-week intervention activities. Exclusion criteria included: (1) having medical restrictions for physical activity; and (2) having cognitive impairments. Initial participants' recruitment was through word-of-mouth personal connection from the St. Louis University, Bosnian friends, and interpreters), flyers distributed in the community, Facebook (Facebook was popular among Bosnians.), a local Bosnian radio station, and local Bosnian organizations and mosques/community centers.

\subsection{Measurements}

The Mental Health Inventory-38 (MHI-38) was adopted to evaluate the effectiveness of physical activity on participants' global mental health. The MHI was part of the National Health Insurance Study and provides an overall assessment of general populations' mental health status, including both psychological distress and psychological well-being. It is a structured and self-reported questionnaire and easy to be administered with minimal instructions from an interviewer [25]. The inventory was adopted by a variety of populations, including adolescents, from different countries (e.g., U.S., China, Germany, Netherland, Israel), and translated into multiple languages. It also has multiple derivatives, such as MHI-38, MHI-37, MHI-30, MHI-26, MHI-18, MHI-5, MHI-3, and MHI-2. A number of studies were conducted to examine the reliability and validity of its different versions and has demonstrated that, overall, it had stable internal consistency and good construct, convergent, and discriminant validity and could provide a reasonable basis for measuring global mental health [26]. The 38-item MHI consists of two global scales: Psychological Distress and
Psychological Well-being and six subscales: Depression, Anxiety, Loss of Behavioral/Emotional Control, General Positive Affect, Emotional Ties, and Life Satisfaction. A higher score on the scales of Anxiety, Depression, Loss of Behavioral/Emotional Control, and Psychological Distress indicate a favorable mental health outcome; a lower score on the scales of General Positive Affect, Emotional Ties, Life Satisfaction, and Psychological Well-being indicates an unfavorable mental health outcome. The MHI-38 also offers the Mental Health Index, a single total score of all 38 items ranged from 38 to 226. The higher Mental Health Index indicates greater psychological well-being and less psychological distress [25]. The approximate administration time of completing this inventory is 15 to 20 minutes. The Inventory was translated into Bosnian for its application to this study.

\subsection{Procedures}

Firstly, using the CBPR approach, two formal community meetings were organized with the participation of Bosnian community representatives, including community informants, religious leaders, interpreters/translators, and Bosnian organization leaders, in a public location. Although a majority of Bosnians reside in South County, they are geographically located in different ethnic sub-communities of South County and other areas of Greater St. Louis. Therefore, Bosnian community representatives were identified from these sub-communities in order to increase the representativeness. The purpose of these meetings was to identify the tailored and culturally appropriate physical activity (e.g., type, intensity, duration, location, organization) for the target population and discuss the logistics of successful study implementation with the community engagement. Each meeting lasted for about 120 minutes. All meetings were accompanied by a professional interpreter. Both the World Health Organization 2010 Global Recommendations for Physical Activity for Health and U.S. Department of Health and Human Services 2008 Physical Activity Guidelines for Americans [27,28], for adults aged 18 to 64 years old to obtain substantial health benefits were used to guide the discussion of these two meetings. Secondly, identified and consented participants were assigned into the intervention and control groups. Each group has 35 participants. All participants received MHI-38 in Bosnian pre- and post-intervention in person. Following the instructions, the participants in the intervention group agreed to conduct at least five 30-minute or three 50-minute moderate-intensity self-selected and monitored physical activity per week for 12 weeks, and keep a journal of the type, time, frequency, and intensity of their physical activity. A trained undergraduate researcher contacted the participants and sent them reminders by mail every week in order to keep track of their performance. Each participant in the intervention group signed a statement in the end of the intervention stating they had completed the 12-week 
recommended physical activity. The control group was determined that they would not conduct any regular physical activity in the next 12 weeks at the beginning of the study. They received educational materials regarding general knowledge/techniques of improving mental health each week for 12 weeks, which were mailed by another trained undergraduate researcher. These materials involve topics in areas of general knowledge/techniques of improving mental health, such as stress management, physical activity and mental health, basic concepts of mental disorders, belief and attitudes towards mental disorders, major risk factors, healthy and effective communication, acculturation of lifestyles and health beliefs, access to mental health services, etc. Each participant in the control group signed a statement in the end stating they had read all the educational materials. The study was approved by the University's Institutional Review Board.

\subsection{Data Analysis}

Quantitative data collected via the MHI-38 were used to perform descriptive statistics and t-tests. MHI-38 provided pre- and post-assessment scores for each of the scales, including the mental health index, two global scales of psychological distress and psychological well-being, and six subscales of anxiety, depression, and loss of behavioral/emotional control, general positive affect, emotional ties, and life satisfaction. In order to examine the effectiveness of physical activity on mental health, paired ttest and two-sample independent t-test were run for comparisons both within the group (intervention or control group) and between the groups (intervention and control groups) on these measures. SPSS 22 software was used to run all the analysis. The significance level will be set at 0.05 (one-tailed).

\section{Results}

A total of 70 participants joined the study with 35 in the intervention and 35 in the control group. A majority of the participants were within an age range of 40 and 64 years old. A total of 16 males and 19 females were in the intervention group in contrast to 17 males and 18 females in the control group. Table 1 indicates the differences between pre- and post-intervention with the intervention group on the MHI-38 scales. After 12-week regular physical activity, the participants made a statistically significant improvement on the scales of Anxiety, General Positive Affect, Psychological Well-being, and overall Mental Health Index (mean difference $=-3.86,3.69,4.89$, and $-14.17 ; \mathrm{p}=.05, .02, .02$, and .01). Although no statistically significant improvement was detected, compared to the participants' mental health status before the intervention in the areas of Depression, Loss of Behavioral/Emotional Control, Emotional Ties, Life Satisfaction, and Psychological Distress, there was noticeable positive change (mean difference $=-1.54$, $-1.17, .37, .26$, and $-8.29 ; \mathrm{p}=.07, .22, .28, .26$, and .06 ).

Table 1. Results of Paired T-test between Pre-and Post-Intervention with the Intervention Group

\begin{tabular}{ccccc}
\hline Scale & $\mathbf{N}$ & $\begin{array}{c}\text { Mean } \\
\text { Difference }\end{array}$ & $\begin{array}{c}\text { Standard } \\
\text { Deviation }\end{array}$ & Sig \\
\hline $\begin{array}{c}\text { Anxiety } \\
\text { Depression } \\
\text { Loss of }\end{array}$ & 35 & -3.86 & 1.92 & $.05^{*}$ \\
$\begin{array}{c}\text { Behavioral/Emotional } \\
\text { Control }\end{array}$ & 35 & -1.54 & 4.92 & .07 \\
$\begin{array}{c}\text { General Positive Affect } \\
\text { Emotional Ties }\end{array}$ & 35 & 3.69 & 8.52 & $.02 *$ \\
$\quad \begin{array}{c}\text { Life Satisfaction } \\
\text { Psychological Distress }\end{array}$ & 35 & .37 & 2.02 & .28 \\
$\quad$ Psychological & .26 & 1.31 & .26 \\
$\quad$ Well-being & 35 & 4.89 & 11.68 & $.02 *$ \\
Mental Health Index & 35 & -14.17 & 32.40 & $.01 *$ \\
\hline *indicates statistical significance & & & \\
\hline
\end{tabular}

Table 2 indicates the differences between pre- and post-intervention with the control group on the two global scales, the overall mental health scale, and the six subscales. After participants in the control group received educational materials concerning mental health for 12 weeks, five out of these nine scales, including Anxiety, Depression, Life Satisfaction, Psychological Distress, and Mental Health Index, stated that the participants in the control group made a statistically significant improvement (mean difference = $-.3 .22,-1.91, .57,-8.26$, and $-10.57 ; \mathrm{p}=.01, .01, .00, .01$, and .02). Positive effects were also identified in the areas of General Positive Affect and Psychological Well-being among the participants in the control group, but they were not significant enough (mean difference $=1.43$ and $1.31 ; \mathrm{p}$ $=.30$ and .47). Both scales of Loss of Behavioral/Emotional Control and Emotional Ties, however, implied that the participants experienced an unfavorable fallback (mean difference $=.34$ and $-.22 ; \mathrm{p}=.55$ and .30 ).

Table 2. Results of Paired T-test between Pre-and Post-Intervention with the Control Group

\begin{tabular}{ccccc}
\hline Scale & N & $\begin{array}{c}\text { Mean } \\
\text { Difference }\end{array}$ & $\begin{array}{c}\text { Standard } \\
\text { Deviation }\end{array}$ & Sig \\
\hline $\begin{array}{c}\text { Anxiety } \\
\text { Depression }\end{array}$ & 35 & -3.22 & 7.01 & $.01^{*}$ \\
$\begin{array}{c}\text { Loss of } \\
\text { Behavioral/Emotional } \\
\text { Control }\end{array}$ & 35 & -1.91 & 3.73 & $.01^{*}$ \\
$\begin{array}{c}\text { General Positive Affect } \\
\text { Emotional Ties }\end{array}$ & 35 & .34 & 3.37 & .55 \\
$\quad 35$ & -.22 & 2.03 & .51 \\
Life Satisfaction & 35 & .57 & .95 & $.00^{*}$ \\
Psychological Distress & 35 & -8.26 & 16.53 & $.01 *$ \\
Psychological Well-being & 35 & 1.31 & 10.72 & .47 \\
Mental Health Index & 35 & -10.57 & 25.59 & $.02 *$ \\
\hline
\end{tabular}

*indicates statistical significance 
Comparisons between the intervention and control groups were also made using the MHI-38 at the baseline before the intervention (Table 3). Based on the mean differences, although the differences between these two groups were not statistically significant, the control group seemed scored more favorably on five scales, including Anxiety, Loss of Behavioral/Emotional Control, Emotional Ties, Psychological Well-being, and overall Mental Health Index (mean difference $=-.08,-1.14, .17, .52$, and $-.26 ; \mathrm{p}$ $=.153, .32, .21, .21$, and .19). On the contrary, the intervention group seemed scored better on the scales of Depression and Psychological Distress (mean difference $=.06$ and $.2 ; \mathrm{p}=.24$ and .23 ). In particular, participants in the intervention group were significantly doing better in Life Satisfaction than those in the control group (mean difference $=-.08 ; \mathrm{p}=.00)$.

Table 3. Results of Independent T-test between Intervention and Control Groups at Pre-Intervention

\begin{tabular}{|c|c|c|c|c|}
\hline Scale & $\mathbf{N}$ & Mean & $\begin{array}{l}\text { Standard } \\
\text { Deviation }\end{array}$ & Sig \\
\hline Anxiety & & & & .153 \\
\hline Intervention & 35 & 39.29 & 9.21 & \\
\hline Control & 35 & 39.37 & 7.64 & \\
\hline Depression & & & & .24 \\
\hline Intervention & 35 & 16.86 & 4.39 & \\
\hline Control & 35 & 16.80 & 4.11 & \\
\hline $\begin{array}{c}\text { Loss of } \\
\text { Behavioral/Emotional } \\
\text { Control }\end{array}$ & & & & .32 \\
\hline Intervention & 35 & 34.83 & 3.30 & \\
\hline Control & 35 & 35.97 & 2.66 & \\
\hline General Positive Affect & & & & .25 \\
\hline Intervention & 35 & 28.09 & 9.98 & \\
\hline Control & 35 & 28.09 & 8.12 & \\
\hline Emotional Ties & & & & .21 \\
\hline Intervention & 35 & 4.54 & 2.60 & \\
\hline Control & 35 & 4.37 & 2.21 & \\
\hline Life Satisfaction & & & & $.00^{*}$ \\
\hline Intervention & 35 & 2.43 & 1.63 & \\
\hline Control & 35 & 2.51 & 1.01 & \\
\hline Psychological Distress & & & & .23 \\
\hline Intervention & 35 & 108.06 & 21.44 & \\
\hline Control & 35 & 107.86 & 18.17 & \\
\hline Psychological Well-being & & & & .21 \\
\hline Intervention & 35 & 38.11 & 14.01 & \\
\hline Control & 35 & 37.86 & 11.68 & \\
\hline Mental Health Index & & & & .19 \\
\hline Intervention & 35 & 166.74 & 33.61 & \\
\hline Control & 35 & 167.00 & 28.35 & \\
\hline
\end{tabular}

*indicates statistical significance
Interestingly, after the intervention, comparisons made between the intervention and control groups showed that the intervention group received more favorable and slightly higher scores on seven scales out of the nine scales, including Anxiety, Loss of Behavioral/Emotional Control, General Positive Affect, Emotional Ties, Psychological Distress, Psychological Well-being, and Mental Health Index (mean difference $=.54, .37,-2.26,-.43, .23,-3.31$, and $3.34 ; \mathrm{p}$ $=.30, .01, .27, .93, .65, .41$, and .88) (Table 4). Unfortunately, all differences were not statistically significant except for the difference on the scale of Loss of Behavioral/Emotional Control $(\mathrm{p}=.01)$. However, the intervention group did not seem to maintain or demonstrate a more favorable mental health outcome after the 12-week regular physical activity on both scales of Depression and Life Satisfaction (mean difference $=-.31$ and $.23 ; \mathrm{p}=.79$ and .1 ).

Table 4. Results of Independent T-test between Intervention and Control Groups at Post-Intervention

\begin{tabular}{|c|c|c|c|c|}
\hline Scale & $\mathbf{N}$ & Mean & $\begin{array}{l}\text { Standard } \\
\text { Deviation }\end{array}$ & Sig \\
\hline Anxiety & & & & .30 \\
\hline Intervention & 35 & 43.14 & 7.40 & \\
\hline Control & 35 & 42.60 & 6.43 & \\
\hline Depression & & & & .79 \\
\hline Intervention & 35 & 18.40 & 3.69 & \\
\hline Control & 35 & 18.71 & 3.35 & \\
\hline $\begin{array}{c}\text { Loss of } \\
\text { Behavioral/Emotional } \\
\text { Control }\end{array}$ & & & & $.01 *$ \\
\hline Intervention & 35 & 36.00 & 4.22 & \\
\hline Control & 35 & 35.63 & 2.57 & \\
\hline General Positive Affect & & & & .27 \\
\hline Intervention & 35 & 24.40 & 9.92 & \\
\hline Control & 35 & 26.66 & 10.19 & \\
\hline Emotional Ties & & & & .93 \\
\hline Intervention & 35 & 4.17 & 2.20 & \\
\hline Control & 35 & 4.60 & 1.97 & \\
\hline Life Satisfaction & & & & .1 \\
\hline Intervention & 35 & 2.17 & .98 & \\
\hline Control & 35 & 1.94 & 1.08 & \\
\hline Psychological Distress & & & & .65 \\
\hline Intervention & 35 & 116.34 & 19.59 & \\
\hline Control & 35 & 116.11 & 16.40 & \\
\hline Psychological Well-being & & & & .41 \\
\hline Intervention & 35 & 33.23 & 13.69 & \\
\hline Control & 35 & 36.54 & 13.43 & \\
\hline Mental Health Index & & & & .88 \\
\hline Intervention & 35 & 180.91 & 31.48 & \\
\hline Control & 35 & 177.57 & 28.72 & \\
\hline
\end{tabular}

*indicates statistical significance 


\section{Discussion}

In sum, after 12-week consecutive regular physical activity, the participants in the intervention group made significant improvement in four areas, including Anxiety, General Positive Affect, Psychological Well-being, and overall Mental Health Index. According to the MHI-38, the participants less frequently felt anxious or frustrated when facing unpleasant or unexpected life events, and were more likely to stay calm and be patient. More frequently, the participants felt happy, hopeful, promising, relaxing, and looking forward to the things that they normally did. They seemed to be more likely to enjoy living their everyday lives. Interestingly, the control group, after receiving 12-week printed educational brochures concerning the concepts of mental disorders, a variety of coping mechanisms of mental disorders, and access to mental health services, they made significant improvement in more areas related to their mental health, including Anxiety, Depression, Life Satisfaction, Psychological Distress, and Mental Health Index. Besides being less likely anxious, less frequently, they stated being down, depressive, moody, and in low spirits. As indicated by the MHI-38, they also appeared to become more and more satisfied with their personal life. Both the intervention and control groups made a predominant positive contribution to their overall mental health during the three-month study period. However, the difference between the two groups after the study activities was not as significant as expected although there was a trajectory implied that the intervention group scored much more favorable in many ways than the control group. At the baseline, the intervention and the control groups only had significantly noticeable difference in the area of Life Satisfaction. The intervention group seemed more satisfied with their personal life before they started their regular physical activity. The two groups were fairly comparable in other areas. At the end of the study, the significant difference between these two was only reflected on the scale of Loss of Behavioral/Emotional Control. Based on the scale, after the 12-week regular physical activity, the intervention group appeared to have a better control of their own thoughts, emotions, feelings, and behaviors than the control group.

Although the intervention group made evident improvements on several aspects of their mental well-being after 12-week regular physical activity, there could be potentials to further strengthen the effectiveness of physical activity among the participants. Over the past five years, research has been focusing more on exploring refugees/immigrants' perspectives of and barriers to physical activity [29-34]. Several studies conducted among Somali and other refugee and immigrant communities with either youth or adults living in the U.S. or overseas indicated that the barriers to their being physically active included lack of motivation to/interest in physical activity, financial constraint, lack of social support for physical activity, lack of culturally appropriate physical activity resources, less opportunities to walk in a western country, unsafe outdoor physical activity, unsupportive social norms for physical activity, unsupportive moral norms for physical activity for females, and poor weather among other reasons provided [29-34]. For instance, Wieland and his colleagues [34] conducted a qualitative study during July and December 2011. A total of 127 Somali, Sudanese, Cambodian, and Mexican refugee and immigrant adults and adolescents were invited to participate in the study by the Rochester Healthy Community Partnership, Minnesota, which was operated under the CBPR principles. Sixteen focus groups were carried out respectively with men, women, boys, and girls to identify their perspectives of and both internal and external barriers to physical activity. The Social Cognitive Theory was adopted as its theoretical framework. In general, the participants presented a good understanding of the definition of physical activity and its health benefits. However, the participants also expressed their concerns about performing regular physical activity, including lack of time due to heavy workload, spending too much time watching TV, being on social media, and playing video games, severe weather, lack of availability and accessibility to gym or places for exercising, gender issues due to family responsibilities, and religion. The participants agreed that they were much less likely to be physically active in the U.S. compared to what they used to be in their country of origin. They believed that if they could be suggested by their doctors or people they trusted for excising; have a community member doing physical activity as their role model; have a companion or a support group for their physical activity; or seriously realize physical activity could be a strong preventive measure for some life-threatening diseases, they would more likely be motivated to be physically active. Murray and his colleagues [30] also used CBPR approach and interviewed eight Somali refugee women resettled in Maine about their challenges of being physically active. The study instrument was designed using both Theory of Planned Behavior and Social Cognitive Theory. Most challenges indicated by this group of women concurred with the ones identified by other Somali refugees living in the U.S. Dressing for exercise or exercising in public seemed to be a major concern among this group due to their religion and cultural norm. Social support was re-emphasized by the participants as a motivator for being physical active.

The CBPR approach was adopted by this study to particularly address the challenges of delivering culturally appropriate physical activity interventions. In this study, participants in the intervention group were allowed to design their own physical activity, such as walking in their favorite shopping malls or parks, walking to Bosnian grocery stores, gardening, indoor activities, climbing stairs, cleaning, lifting heavy objects, and playing soccer, which was most suitable to their religion, schedule, physical condition, social norm, and etc. as long as they met the general study requirement for frequency, intensity, and duration of regular physical activity. The participants also received weekly reminders through mail to motivate them to keep going. However, the 
feedback received from the intervention group suggested that their performance was sometimes interfered by factors, including body aching, feeling tired, and lack of motivation for continuum, which were consistent with the previous findings. Therefore, future physical activity interventions for Bosnian communities may consider being enhanced by applying more multidisciplinary motivational strategies in order to further address the cultural perspectives of and barriers to physical activity, improve the effectiveness of physical activity interventions, and sustain long-term physical activity among the community members. These strategies include, such as (1) delivering a community-based social marketing campaign to increase awareness and change social norms of the relationship between physical activity and health and how to properly conduct physical activity; Social marketing/mass media campaigns have been proven to be general effective to promote physical activity [35-42]. For instance, in 2002, CDC launched a nationally representative social marketing campaign $\left(\mathrm{VERB}^{\mathrm{TM}}\right)$ to promote physical activity among multiethnic youth aged nine to 13 years old as the primary targeting population and their parents, teachers, and other supporting parties as the secondary targeting population within nine-selected communities in the U.S. Commercial media marketing strategies were heavily adopted through using TV, radio, print in order to sell the product, being physical active, to the youth and the ones who had a significant impact on them. The four P concepts of Product, Price, Place, and Promotion in social marketing were well-integrated into the Campaign. Both baseline and follow-up data were collected to evaluate the effectiveness of the Campaign [42]. Effectiveness appeared to be very favorable after one-year, two-year, and four-year follow-up. Findings suggested the Campaign achieved its outcome expectations. The impact on youth awareness, belief, and behavior about physical activity was statistically significant. Youth were more engaged in both free-time and organized physical activity. There was a dose-response relationship between the levels of awareness of physical activity and the levels of physical activity [36-38]. Likewise, a three-year national social marketing campaign, ACTIVE for LIFE, was implemented in England. Evaluation of the effectiveness was conducted among a nationally representative random cohort of 3,189 adults aged 16-74 years concerning their awareness, knowledge, and skills of physical activity. Participants become more ready for being physically active than they were before the Campaign [35]. Our previous research findings showed that the middle-aged and older Bosnians in St. Louis tended to rely on traditional media channels, such as radio and television, whereas the younger Bosnian-Americans relied more on social media, such as internet [40]. (2) Organizing support groups and identifying group leaders for physical activity within a Bosnian community; Bosnian communities are highly cohesive, and Bosnians are very social. They enjoy doing activities together, and they respect their community/religious leaders and role models. The effectiveness of social support and a role model on physical activity among refugee and immigrant populations have also been suggested by the most recent literature [29-34]. And (3) Using objective measures to identify the participants' behavioral patterns for physical activity in order to pinpoint and fill any potential gaps relevant to participants' behavioral consistency. The current intervention activities were self-monitored and self-reported. Future study participants may be encouraged to wear an electronic device, such as ActiGraph Model GTX3+, so that researchers can remotely and objectively measure the density, duration and frequency of participants' physical activity.

\section{Conclusions}

Overall, the preliminary findings suggest the intervention study has been proven to be effective among both intervention and control groups. To our knowledge, this is a pilot physical activity intervention study to improve Bosnian refugees' mental health in the U.S., which sets the precedent for future similar non-clinical mental health interventions among other Bosnian and other refugee and immigrant communities. The CBPR approach helped identify the culturally appropriate physical activities for the study participants, improve the likelihood of sustainability of intervention activities, and increase the general interest in and motivation for physical activity afterwards. Future endeavor may focus on, under the CBPR guideline, using interdisciplinary approach to collaboratively develop and deliver a social marketing campaign and a physical activity intervention with a Bosnian community through applying appropriate communication strategies and channels in health communication, motivational/behavioral change theories in exercise psychology, and objective measurements/indicators for physical activity in exercise science in order to address the current study's deficiency for a mental health concern in public health. It will provide a strong demonstration of the effectiveness of an interdisciplinary application of public health, health communication, exercise psychology, and exercise science in promoting mental health among underserved and underrepresented populations. It will also provide cross-disciplinary training to faculty, students, and community researchers, as well as significantly enhance the levels of cultural competency among professionals within and outside these four disciplines.

\section{REFERENCES}

[1] M. Fazel, J. Wheeler, J. Danesh. Prevalence of serious mental disorder in 7000 refugees resettled in western countries: A systematic review, Lancet, Vol. 365, 1309-14.

[2] L. J. Kirmayer, et al. Common mental health problems in 
immigrants and refugees: general approach in primary care, Canadian Medical Association Journal, Vol. 183, No. 12, E959-967.

[3] M. Mölsä, R. L. Punamäkic, S. L. Saarni, M. Tiilikainen, S. Kuittinen, M. L. Honkasalo, M. L. Mental and somatic health and pre- and post-migration factors among older Somali refugees in Finland, Transcultural Psychiatry, Vol. 51, No. 4, 499-525.

[4] H. B. Ellis, H. Z. MacDonald, A. K. Lincoln, H. J. Cabral. Mental Health of Somali Adolescent Refugees: The Role of Trauma, Stress, and Perceived Discrimination, Journal of Consulting and Clinical Psychology, Vol. 76, No.2, 184-193.

[5] Fazel, M., Reed, R. V., Panter-Brick, C., \& Stein, A. (2012). Mental health of displaced and refugee children resettled in high-income countries: risk and protective factors,. Lancet, 379:266-82.

[6] F. Lindencrona, S. Ekblad, E. Hauff. Mental health of recently resettled refugees from the Middle East in Sweden: the impact of pre-resettlement trauma, resettlement stress and capacity to handle stress, Social Psychiatry and Psychiatric Epidemiology, Vol. 43, 121-131.

[7] M. T. Abou-Saleh, P. Hughes. Mental health of Syrian refugees: Looking backwards and forwards, Insight, Vol. 2, No. $10,870-871$.

[8] Betancourt, T. S., Frounfelker, R., Mishra, T., Hussein, A., \& Falzarano, R. (2015). Addressing Health disparities in the mental health of refugee children and adolescents through community-based participatory research: A study in 2 communities, American Journal of Public Health, 105:S475-S482.

[9] S. Y. Li, B. J. Liddell, J. Nickerson. The relationship between post-migration stress and psychological disorders in refugees and asylum seekers, Current Psychiatry Report, Vol. 18, 82-90.

[10] M. Mölsä, S. Kuittinenc, M. Tiilikainend, ML. Honkasaloef, RL. Punamäkic, RL. Mental health among older refugees: the role of trauma, discrimination, and religiousness, Aging and Mental Health, Vol. 20, No. 10, 1-9.

[11] B. Morton, H. Feng. Mental health effects of premigration trauma and postmigration discrimination on refugee youth in Canada, Journal of Nervous \& Mental Disease, Vol. 204, No. $6,464-470$.

[12] R. F. Mollica, K. McInnes, N. Sarajlic, J. Lavelle, I. Sarajlic, M. P. Massagli. Disability associated with psychiatric comorbidity and health status in Bosnians living in Croatia, JAMA, Vol. 282, 433-439.

[13] R. F. Mollica, K. McInnes, N. Sarajlic, J. Lavelle, I. Sarajlic, M. P. Massagli. Longitudinal study of psychiatric symptoms, disability, mortality, and emigration among Bosnian refugees, JAMA, Vol. 28, No. 5, 546-554.

[14] K. Sundquist, L. M. Johansson, V. DeMarinis, S. K. Johansson, J. Sund[

[15] uist, J. Posttraumatic stress disorder and psychiatric co-morbidity: Symptoms in a random sample of female Bosnian refugees, European Psychiatry, Vol. 20, 158-164.

[16] S. M. Weine, S. M., et al. PTSD symptoms in Bosnian refugees 1 year after resettlement in the United States, American Journal of Psychiatry, Vol. 155, 562-564.

[17] J. Firth, J. Cotter, R. Elliott, R. French, A. R. Yung, A. R. A systematic review and meta-analysis of exercise interventions in schizophrenia patients, Psychological Medicine, Vol. 45, 1343-1361.

[18] M. Pratt, J. N. Epping, W. H. Dietz. Putting physical activity into public health: A historical perspective from the CDC, Preventive Medicine, Vol. 49, 301-302.

[19] S. Rosenbaum, A. Tiedemann, C. Sherrington, J. Curtis, P. B. Ward. Physical activity interventions for people with mental illnesses: A systematic review and meta-analysis, Journal of Clinical Psychiatry, Vol. 75, No. 9, 964-974.

[20] M. L. Wieland, et al. Physical activity and nutrition among immigrant and refugee women: A community-based participatory research approach, Women's Health Issues, Vol. 22, No. 2, e225-e232.

[21] International Institute-St. Louis, 20,000th refugee is sponsored by International Institute. St. Louis, MO, Online Available from http://www.stlbosnians.com/20000-th-refugee-is-spons ored-by-international-institute/

[22] Agency for Healthcare Research and Quality, U.S. Department of Health and Human Services, Community-based participatory research: Assessing the evidence, Online available from http://www.ncbi.nlm.nih.gov/books/NBK118 $52 /$

[23] D. S. Blumenthal. Is community-based participatory research possible? American Journal of Preventive Medicine, Vol. 40, No. 3, 386-389.

[24] K. Love. Little known but powerful approach to applied research: Community-based participatory research, Geriatric Nursing, Vol. 32, No. 1, 52-54.

[25] A. Strohle. Physical activity, exercise, depression and anxiety disorders, Journal of Neural Transmission, Vol. 116, 777784 .

[26] Australian Mental Health Outcomes and Classification Network, Mental Health National Outcomes and Casemix Collection: Overview of clinician-rated and consumer self-report measures, Version 1.50. Department of Health and Ageing, Canberra, 2003. Mental health Inventory-38. Online Available from http://amhocn.org/static/files/assets/8d6994c 3/Mental_Health_Inventory.pdf

[27] P. Cuijpers, N. Smits, T. Donker, M. T. Have, M. T., R. D. Graaf. Screening for mood and anxiety disorders with the five-item, the three-item, and the two-item Mental Health Inventory, Psychiatry Research, Vol. 168, 250-255.

[28] World Health Organization, Global recommendations on physical activity for health, Online Available from http://whqlibdoc.who.int/publications/2010/9789241599979 _eng.pdf

[29] U.S. Department of Health and Human Services, Physical Activity Guidelines for Americans, Online Available from http://www.health.gov/PAGuidelines/pdf/paguide.pdf

[30] J. T. Devlin, D. Dhalac, A. A. Suldan, A. Jacobs, K. Guled, K. A. Bankole. Determinants of physical activity among Somali women living in Maine. Journal of Immigrant and Minority 
Health, Vol. 14, 300-306.

[31] K, Murray, A. S. Mohamed, D. B. Dawson, M. Syme, S.Abdi, J. arnack-Tavlaris. Somali perspectives on physical activity: Photovoice to address barriers and resources in San Diego, Progress in Community Health Partnerships, Vol. 9. No. 1, $83-90$.

[32] G. Persson, A. J. Mahmud, E. E. Hansson, E. L. Strandberg. Somali women's view of physical activity - a focus group study, BMC Women's Health, Vol. 14, 129-139.

[33] E. Rothe, et al. Barriers to outdoor physical activity in wintertime among Somali youth, Journal of Immigrant and Minority Health, Vol. 12, 726-736.

[34] J. P. Rotich. Physical activity participation related challenges that adolescent Montagnard refugee youth encounter in America, International Journal of Human Sciences, Vol. 11, No. $1,45-54$.

[35] M. L. Wieland, et al. Perspectives on physical activity among immigrants and refugees to a small urban community in Minnesota, Journal of Immigrant and Minority Health, Vol. 17, 263-275.

[36] M. Hillsdon, N. Cavill, K. Nanchahal, A. Diamond, I. R. White. National level promotion of physical activity: Results from England's ACTIVE for LIFE campaign, Journal of Epidemiology and Community Health, Vol. 55, No, 755-761.
[37] M. Huhman, L. D. Potter, F. L. Wong, S. W. Banspach, J. C. Duke, C. D. Heitzler. Effects of a mass media campaign to increase physical activity among children: Year-1 results of the VERB campaign, Pediatrics, Vol. 116, No, 2, e277-284.

[38] M. E. Huhman, et al. Evaluation of a national physical activity intervention for children VERB ${ }^{\mathrm{TM}}$ campaign, 2002-2004, American Journal of Preventive Medicine, Vol. 32, No. 1, 38 $-43$.

[39] M. E. Huhman, et al. The influence of the VERB campaign on children's physical activity in 2002 to 2006, American Journal of Public Health, Vol. 100, 638-645.

[40] J. E. Leavy, F. C. Bull, M. Rosenberg, A. Bauman, A. Physical activity mass media campaigns and their evaluation: A systematic review of the literature 2003-2010, Health Education Research, Vol. 26, No. 6, 1060-1085.

[41] A. Karamehic-Muratovic. Post-Conflict Mental Health of Bosnian Refugee Women, Midwest Sociological Society Meeting, Chicago, IL

[42] D. K. Wilson, et al. Qualitative developmental research among low income African American adults to inform a social marketing campaign for walking, International Journal of Behavioral Nutrition and Physical Activity, Vol. 10, 33-38.

[43] F. Wong, et al. VERB ${ }^{\mathrm{TM}}$-A social marketing campaign to increase physical activity among youth, Preventing Chronic Disease, Vol. 1, No. 3, 1-7. 